\title{
A QUESTÃO DA TÉCNICA EM OSWALD SPLENGER ${ }^{1}$
}

Francisco Romulo Alves Diniz ${ }^{2}$

\begin{abstract}
Resumo:
O pensamento de Spengler em relação à técnica se insere no contexto da relação entre a técnica e seu impacto na cultura ocidental contemporânea, sendo um dos trabalhos pioneiros e que invoca uma série de problemas conforme poder-se-á conferir no desenvolvimento deste artigo. O que se pretende demonstrar é a visão cíclica e metafísica da técnica, e ainda apontar que tal visão é decorrente do método morfológico por ele utilizado na Decadência do Ocidente. As discussões passarão por autores significativos como Heidegger e outros que se debruçaram na obra de Spengler para de lá escrutinar algum sentido para a história. Este artigo toma como obra central o pequeno livro intitulado $O$ homem e a técnica, publicado em 1931.
\end{abstract}

Palavras-chaves: Técnica. Poder. Decadência. Ocidente.

\section{THE QUESTION OF TECHNIQUES IN OSWALD SPLENGER}

\begin{abstract}
:
Spengler's thinking about technique is inserted in the context of relationship between the technique and its impact on contemporary western culture, being one of the pioneering works and that invokes a series of problems as can be seen in the development of this article. What is intended to be demonstrated is the cyclical and metaphysical view of the technique, and also to point out that such view is due to the morphological method used by him in the Decadence of the West. The discussions will go through significant authors such as Heidegger and others who looked at Spengler's work to scrutinize some sense of history from there. This article takes as it's central work the small book entitled The man and the technique, published in 1931.
\end{abstract}

Keywords: Technique. Power. Decadence. West.

\section{Introdução}

Oswald Spengler (1880 - 1936), nascido em Blankenburg, Alemanha, é hoje um historiador, matemático e filósofo quase esquecido. No entanto, em 1918 publicou o primeiro tomo de sua obra chave, A decadência do Ocidente, e obteve um reconhecimento público notório em pouco tempo. O segundo volume apareceria 4 anos depois. A obra apresenta um cunho pessimista e, ao mesmo tempo, conservador sobre o futuro, tanto da Alemanha quanto da Europa pós-primeira guerra.

1 Artigo apresentado no I Encontro Nacional de Filosofia da Técnica e Educação (ENFITE), realizado de 06 a 08 de agosto de 2019, na Universidade Estadual Vale do Acaraú (UVA), na cidade de Sobral/CE.

2 Doutor em Filosofia pela Universidade Federal da Paraíba. Professor do Curso de Filosofia da Universidade Estadual Vale do Acaraú, atuando na graduação e no Mestrado Acadêmico em Filosofia. Professor dos Cursos de Direito, Psicologia e Enfermagem da Faculdade Luciano Feijão. E-mail: romulodiniz40@gmail.com. 
Pretende-se, nesse artigo, revisitar as ideias presentes num pequeno livro intitulado Der Menschund die Technik, datado de 1931, com o propósito de apontar que Spengler foi capaz de ler, por um lado, nos eventos que se desenrolaram na primeira metade do século XX, sobretudo no contexto da primeira guerra mundial, o papel que a técnica ocuparia no desenvolvimento e numa possível derrocada do ocidente. Por outro lado, essa exposição é um convite para, primeiro, conhecer a filosofia presente em um autor pouco estudado na academia atualmente; segundo, para examinar se suas teses trazem algo significativo sobre a técnica e a ciência nos dias atuais; terceiro, independentemente do seu pessimismo e abstrações quase imaginárias, situá-lo como um pensador que enxergou na técnica um modo definidor do ser do homem.

Spengler viveu, publicou e faleceu num dos períodos mais turbulentos da história alemã contemporânea. Ele foi capaz de capturar os sentimentos prevalentes na instável sociedade do período ante e pós-primeira guerra mundial. Também enxergou os eventos políticos que assumiram uma abrangência ainda não registrada na história, como uma guerra de proporções universais. A universalidade do conceito assumido pelos idealistas se fazia notar na crueza das batalhas. A Decadência do ocidente é um registro daquele momento (GOMES, 2013).

Na obra magna de Spengler se percebe a junção do método morfológico de Goethe com o modo provocativo de colocar os problemas inaugurados por Nietzsche (GOMES, 2013, p. 16). Nela, também se faz presente a discussão entre Kultur und Zivilization que dominou os palcos da cultura germânica na modernidade tardia. Essa discussão permite inferir o título da obra de Spengler. Ambivalência de sentimentos que deslizam entre o pessimismo e a esperança podem aí ser encontrados.

Isso pode ser percebido numa comparação ao pensamento de Heidegger, ao desvelar a ambiguidade (otimismo ou pessimismo) da técnica, com base em um poema de Hördelin:

Wo aber Gefahr ist / wächst das Rettendea uch": "Dónde hay peligro / crece lo que nos salva." O: "crece lo salvador" - la técnica tiene una potencialidad salvadora, que está disimulada en ella ("verstellt") y que la cultura occidental aun no logra liberar ${ }^{3}$ (NITSCHACK, 2016, p. 165).

Nessa época os ideais iluministas são postos à prova, a filosofia idealista experimenta o declínio e a Alemanha parece ter perdido o rumo em relação à sua

\footnotetext{
${ }^{3}$ Tradução livre: "Onde há perigo, cresce o que nos salva. Cresce o Salvador - a técnica tem uma potencialidade salvadora, que está escondida nela e que a cultura ocidental ainda não conseguiu liberar". 
história e também como condutora dos destinos da Europa. Todos esses sentimentos se fazem perceber principalmente no período da república de Weimar e de uma Alemanha derrotada e humilhada.

Cabe aqui uma breve observação sobre a concepção de história em Spengler. De acordo com Swer (2019) a concepção de história em Spengler se caracteriza como especulativa, cíclica e preocupada mais com a fenomenologia existencial dos acontecimentos do que com a história propriamente dita. Desse modo, justifica-se o modo como abordaremos a análise acerca da relação do homem com a técnica.

\section{Sobre o homem e a técnica}

Spengler abordou entre outros temas a questão da técnica e tecnologia modernas e como elas interferem na auto concepção do homem. Segundo Swer (2019, p. 01), "Spengler's analysis emphasises the metaphysical nature of the mathematical and its role in underpinning modern science and the technological mode of contemporary human existence". 4 Assim, sua visão e seu método parecem extrínsecos aos acontecimentos da história, os forçando a um encaixe metafísico, promovendo um diagnóstico falho da modernidade. ${ }^{5}$

$O$ homem e a técnica resumem não apenas os sentimentos, mas também uma espécie de caminho possível após o período de Weimar. Ele é composto de cinco capítulos: um primeiro, no qual se articula a técnica como tática vital; o segundo, que procura definir o homem ou mesmo incluí-lo como o predador par excelence; a mão

\footnotetext{
${ }^{4}$ Tradução livre: "a análise de Spengler enfatiza a natureza metafísica da matemática e seu papel na sustentação da ciência moderna e do modo tecnológico da existência humana contemporânea".

${ }^{5}$ No artigo intitulado Technology and the End of Western Civilisation: Spengler's and Heidegger's Histories of Life/Being (2019) Swer faz uma análise das influências que Heidegger sofre da visão de Spengler e busca neles uma proximidade. Ele advoga que há uma similaridade entre os dois modelos de pensamento: "Heidegger and Spengler operate with a rather singular understanding of the mathematical and the significance of its foundational role in technological modernity" (SWER, 2019, p. 2). (Tradução livre: Heidegger e Spengler operam com uma compreensão bastante singular da matemática e do significado de seu papel fundamental na modernidade tecnológica). Um pouco mais adiante enfatiza, "For both thinkers, the mathematical, in its originary sense, is a projection made upon the world that anticipates and orders the way in which entities come to presence" (SWER, 2019, p. 2). (Para ambos os pensadores, a matemática, em seu sentido original, é uma projeção feita no mundo que antecipa e ordena a maneira pela qual as entidades vêm à presença. Noutra passagem, indica Swer, "for both thinkers, modern science is the harbinger of technology" (2019, p. 5). (Para ambos, a ciência moderna é o prenúncio da tecnologia).
}

\begin{tabular}{|c|c|c|c|c|}
\hline Q Rovita Dialectus & Ano 9 & n. 17 & Maio - Agosto 2020 & p.244-257 \\
\hline
\end{tabular}


como a parte que toca e modifica o mundo e o instrumento como extensão e seus modos de usos; a linguagem que engendra o empreendedorismo e como isso se torna cultura; e, por fim, analisa a ascensão e a dissolução da cultura mecanicista ou fáustica. Para Spengler (1993, p. 97), “A cultura faústica, ou seja, a da Europa Ocidental, se não é, por acaso, a última, é decerto a mais poderosa, a mais vibrante”. Essa vibração tem entre seus elementos o pendor para a ciência e a técnica.

Doravante, far-se-á uma demonstração, seguindo os passos do autor no seu pequeno livro, com vistas a apontar para uma visão também especulativa, cíclica e metafísica da técnica. A primeira parte do livro trata de destacar a técnica como um modo próprio de vida em constante luta. Para tanto, Spengler indica os animais herbívoros e os carnívoros e suas respectivas técnicas de sobrevivência.

Spengler analisa a técnica sob o signo da luta. Ele não entende a técnica como um conjunto de ações construídas para alcançar um fim imediato - a estratégia ou conjunto articulado de elementos cujo fim é produzir um determinado resultado simplesmente ${ }^{6}$. A técnica tem, para ele, um lugar natural: não é um puro artifício da razão calculadora, mas forma de luta e sobrevivência das espécies. Assim, verá também o espaço de sobrevivência do homem no campo político.

A tese subjacente à questão da técnica é, antes de tudo, antropológica. Spengler pergunta pelo homem: quem é ele? A sua resposta vai no mesmo sentido do capítulo anterior, isto é, ele o define considerando o ambiente em luta: um organismo em luta com e contra o próprio ambiente, sendo, portanto, um organismo de natureza bélica. Logo na primeira linha do terceiro capítulo ele o anuncia: "o homem é um animal predador"! Tal versão, se não se choca com as definições cristalizadas sobre o homem, como Zoon Politikon e como animal racional, apresenta um sentido novo e latente às dimensões da política e da racionalidade. Para Spengler, o que define o ser humano é essa condição primeira em luta constante no e com o ambiente. Essa é uma posição que não é nova - basta lembrar Michel de Montaigne em Os Canibais (1580) e também nos Ensaios (1580) em Nietzsche em várias passagens de sua obra.

Esse predador, no enquanto, é também o mais digno, indica Spengler (1993, p. 52). Nos seus termos podemos conferir:

\footnotetext{
6 De acordo com Franz Brüseke (2000, p. 13) "A técnica moderna transcende a racionalidade de fins, que não deixa de existir, para fazer surgir meios que buscam posteriormente os seus fins". Porém, isso só ocorre na modernidade quando se alinham a ciência, a técnica e a empresa capitalista.

\begin{tabular}{|c|c|c|c|c|}
\hline Revista Dialectus & Ano 9 & n. 17 & Maio - Agosto 2020 & p.244-257 \\
\hline
\end{tabular}
}


(...) o herbívoro está predestinado a ser uma presa e em vão tenta subtrair-se a esse destino, pela fuga, mas o predador, por seu lado tem de atingir uma vítima. A vida do primeiro transcorre pela fuga, mas o predador, por seu lado, tem de atingir uma vítima. Assim, a vida do primeiro é defensiva na sua mais íntima essência a do segundo é agressiva, dura, cruel, destruidora.

Nessa passagem Spengler tenta naturalizar a luta e justificar o ser predador como forma de ser e sobreviver do homem; sua sobrevivência dependeria dessa condição predatória. Essencialmente seria o homem um ser que não tem como escapar dessa condição sui generis: é predador.

As suas teses em relação às teorias da percepção animal foram contestadas pela zoologia posterior. O recorte realizado por ele parece intencional e, às vezes, místico e eivado de aspectos metafísicos. Isso se pode perceber no destaque que ele dá a aspectos do corpo animal, principalmente dos predadores de determinadas espécies, como as aves de rapina. Estes possuem sempre uma mira e uma meta. Diz Spengler (1993, p. 53): “(...) no olhar do inimigo está já, para a vítima, o destino inelutável, o salto que nos momentos seguintes se fará”, e acrescenta ainda que a imagem do mundo é a de um mundo circuncidado pelos olhos: “(...) o mundo, esse assim, é a presa; neste fato reside, em última análise, a fonte de toda a cultura humana" (SPENGLER, 1993, p. $54)$.

Dos olhos à alma. Esta, “(...) cuja essência escapa a qualquer ciência” (SPENGLER, 1993, p. 54), faz de cada coisa exatamente o que ela é. Aqui Spengler mergulha numa espécie de misticismo metafísico insondável; às vezes não parece ser herdeiro de Nietzsche ${ }^{7}$. No entanto, interpretando Schopenhauer e Darwin, para quem a luta pela vida era o triste destino das espécies, mas ao mesmo tempo o nódulo que enobrece e confere significado à vida, ou o amor fati de Nietzsche, prescreve a aceitação do destino irremediável do próprio mundo. Spengler conclui que o homem pertence a essa categoria de seres ativos, cujo fim é o domínio. Para ele (1993, p. 56), “(...) a tática vital do homem é a de um soberbo predador, intrépido, astuto e cruel. Vive agredindo, matando e destruindo. Desde que existe, o homem aspira ao domínio".

A partir desse ponto podemos tratar especificamente da técnica em Spengler, muito embora, acreditamos que já se tenham inferido alguma das posições dele a partir das premissas acima indicadas. Um dos pontos é que a característica

7 Um dos pontos centrais da crítica de Nietzsche em sua filosofia é dirigido à metafísica tradicional, principalmente a de cunho religioso, ainda que Heidegger indique que a filosofia de Nietzsche seja também marcada por traços metafísicos (Cf. HEIDEGGER, 2000).

\begin{tabular}{|l|l|l|l|l|}
\hline Revista Cialectus & Ano 9 & n. 17 & Maio-Agosto 2020 & p.244-257 \\
\hline
\end{tabular}


exclusiva da técnica humana está radicada no fato dela ser independente da vida da espécie humana. Não estamos programados para a produção de uma única alternativa para a resolução de problemas semelhantes. Segundo Spengler (1993, p. 58), “(...) o homem é, em toda a história dos seres vivos, o único exemplo, capaz de escapar a coesão da espécie”. Na existência humana a técnica é consciente, voluntária, suscetível de modificação, pessoal, imaginativa e inventiva (SPENGLER, 1993, p.58). Desse modo, o homem se torna criador de sua própria técnica vital e nisto consiste a sua grandeza e, ao mesmo tempo, a sua fatalidade.

No entanto, Spengler questiona como o homem chega ou se torna homem. A resposta de Spengler é: pela mão. Ela que identifica os objetos no espaço: “(...) a mão não só distingue o calor e o frio, o sólido e o líquido, o duro e o mole, mas também e, acima de tudo, o peso, a forma, a relação entre as diversas resistências" (SPENGLER, 1993, p. 61), a mão serve não apenas para tatear como também para agir. Ele atribui à mão o poder da ação. Privilegia-se o fazer, o realizar. Ela é essencialmente finalista. Sua existência é funcional. É essa funcionalidade anterior a outras funções como o pensar ou mesmo o sentir.

A fisiologia da mão aponta para além de si mesma. Sua direção é exterior. Visa o outro do mundo. Nesse sentido, indica que o outro difere de si e, pode ser, por ela, apropriada, tornada sua. A mão pode indicar, assim, um processo de individuação e diferenciação. De interiorização quando torna o estranho - do mundo - parte sua, e de exteriorização quando se utiliza para outros fins.

Spengler associa dois sentidos fundamentais: a visão que configura o predador, indicado anteriormente, associado à mão e ao sentido do tato, além de outras funções a ela atribuída. Pela mão o homem modifica o mundo. Transforma-o e também o deforma. A tese sobre o surgimento desse acontecimento também pode ser refutada, pois Spengler não é um defensor da teoria evolucionista da Darwin. No entanto, ele indica que o surgimento da mão está associado ao utensílio, pois, "a mão exige a arma, para poder ser ela própria uma arma" (SPENGLER, 1993, p. 63). Assim, os homens do passado remoto podem ser reconhecidos pelos utensílios que utilizaram. A antropologia cultural e material nos dá uma noção de como viveram. A ferramenta utilizada é um registro da própria história humana. A dissociação é prejudicial à compreensão de quem eram e de como agiam.

\begin{tabular}{|c|c|c|c|c|}
\hline Q Rovista Dialectus & Ano 9 & n. 17 & Maio - Agosto 2020 & p.244-257 \\
\hline
\end{tabular}


Para Spengler, “(...) nenhum outro predador seleciona suas armas” (1993, p. 64). Ele não apenas escolhe, mas as fabrica em conformidade com as intenções, e isso lhe deu superioridade na luta contra os demais e também contra a natureza. Foi esse fato que possibilitou que o homem se livrasse da coação da espécie (SPENGLER, 1993, p. 64). Spengler os resume em "pensar olhos" e "pensar mão". Da estratégia para a técnica, do pensar, elaborar, criar, para a ação: “(...) do primeiro se origina o pensamento teórico, observador, contemplativo - o que chamamos o raciocínio, a sabedoria, - e do segundo nasce o pensamento prático e atuante, a nossa astúcia e a nossa inteligência propriamente ditas" (SPENGLER, 1993, p. 65).

A partir dessa divisão, Spengler faz uma classificação dos homens, pois foi de tais princípios que nasceram os homens da verdade - sacerdotes, filósofos e cientistas - e os de ação - estadistas, generais, comerciantes. E arremata Spengler (1993, p. 66): “desde tal época até nossos dias a mão, dominadora, imperiosa e fechada passou a ser símbolo da vontade (...)”; grafologias, quiromancias e metáforas daí surgiram, como, por exemplo, "a mão pesada da lei". Assim, a capacidade criadora do homem seguiu, para Spengler, a mão, o pensamento e a arma. Como criador, aquilo que doravante era considerado natural é tornado humano. Um exemplo direto que aqui se pode citar é o fogo: uma vez dominado é recriado na esfera da vida, pelo homem, contra a natureza, para lembrarmos a ação de Prometeu, o pai de toda a tecnologia.

Uma vez respondido quem é o homem, cabe agora examinar essa alma. Spengler a caracteriza como solitária, visionária e orgulhosa, pois arca com a melancolia do ser que conhece o seu destino. Acrescenta ele: “(...) uma alma impregnada da sensação do poder ilimitado proporcionado por essa mão cerrada, pronta para agir; uma alma inimiga de tudo, que mata, odeia, que está disposta a vencer ou a morrer" (SPENGLER, 1993, p. 67). Em suma, a alma de um rebelde. E, conclui ele, após uma breve análise das hordas primitivas: “(...) a alma desse poderoso solitário é beligerante, desconfiada, zelosa do seu poder pessoal e de sua presa (...) todo o homem autêntico, mesmo o que vive nas cidades em períodos de maturidade das culturas, sente, de vez em quando, no seu íntimo, os ardores dessa alma primitiva" (SPENGLER, 1993, p. 68). O progresso técnico é sintoma dessa alma, pois, na medida em que se avança em direção ao domínio pleno do ponto de vista científico e técnico, a alma se afasta cada vez mais da natureza; dela se diferencia e esse distanciamento a coloca no lugar de presa.

\begin{tabular}{|c|c|c|c|c|}
\hline Qovista Dialoctus & Ano 9 & n. 17 & Maio - Agosto 2020 & p.244-257 \\
\hline
\end{tabular}


O passo seguinte da argumentação de Spengler é mostrar que houve uma evolução a partir do momento em que o homem passou a realizar ações coletivas combinadas, ou como hoje compreendemos, começou a empreender. Foi ele que exigiu o desenvolvimento e aperfeiçoamento da linguagem: a linguagem está para o empreendimento como a mão está para o utensílio. O empreendimento de ações para atender às necessidades vitais - estas se apresentaram sempre como primordiais exigiram o desenvolvimento da linguagem e suas formas variadas de articulações (sob a forma de línguas diversas).

É a linguagem que estabelece o elo entre as pessoas através do empreendimento; percebe-se aqui que o movimento é de fora para dentro. Spengler indica que “(...) o hábito de empreender foi se disciplinando e aperfeiçoando graças ao concomitante aperfeiçoamento dos processos mentais vinculados à palavra e à linguagem" (SPENGLER, 1993, p. 79). A palavra é um ato de matriz intelectual que se põe em prática com o auxílio dos sentidos, conclui Spengler.

Relembremos: para Spengler o homem é um predador, marcado essencialmente pela visão e pela mão. Pelo ver, projetar e pelo fazer. No entanto, há uma inversão nesse processo, pois o homem se define na busca constante para ampliar sua força e ter êxito na luta. Em função de obter mais poder sacrificará uma parte significativa da sua vida, pois gradualmente se entrega ao pensamento e ao cálculo, resultados do desejo de domínio, tornando-se, assim, servo do seu pensamento. Ele enreda-se na sua própria teia de pensamentos e ideias de modo que produz concepções de mundo e de alma desvinculados do mundo prático. O físico e o metafísico são aqui postos como resultado do desenvolvimento da linguagem que, ao se complexificar, enreda-se nos seus próprios modos de se estabelecer, criando uma teia que se desvincula do real e gerando um campo que será classificado como metalinguagem ${ }^{8}$.

Há muitos processos esquecidos ao longo da história humana pelo próprio distanciamento que o homem se pôs. Nesse sentido, basta lembrarmo-nos dos inúmeros processos técnicos desenvolvidos e depois esquecidos ou perdidos, como o das construções megalíticas de povos como os Incas, Astecas e Maias, apenas para citar os mais próximos.

Não há apenas processos de construção ao longo da história, mas também de alteração e modificação quando, por exemplo, iniciaram-se os processos de

8 A esse respeito conferir os trabalhos de Noam Chomsky, em especial, Syntactic Structures (1957), Linguagem e mente (1998) e Reflexões sobre a linguagem (1980).

\begin{tabular}{|l|l|l|l|l|}
\hline Rovita Cialectus & Ano 9 & n. 17 & Maio-Agosto 2020 & p.244-257 \\
\hline
\end{tabular}


domesticação de animais e plantas. Atualmente esses processos atingiram níveis extraordinários de conhecimento científico e técnico, pois se consegue, através de manipulação genética, produzir órgãos ou produzir sementes resistentes a pragas, mas que podem, ao mesmo tempo, produzir efeitos não previsíveis nos organismos que deles se alimentam.

Para Spengler da vinculação entre linguagem e empreendedorismo derivam duas categorias de homens. Eles se diferenciam de acordo com suas capacidades: os nascidos para mandar e outros para obedecer (SPENGLER, 1993, p. 84), os agentes e os pacientes. Desse modo se passa da concepção de mundo natural para o mundo da política, da cultura ou o mundo artificial. Nos seus termos: “(...) governar, decidir, dirigir, comandar - eis uma arte difícil, uma técnica peculiar, que exigem, como qualquer outro caso, um talento inato" (SPENGLER, 1993, p. 85). Ele aqui revela sua posição política e como supostamente deve ser, considerando que pela política se atingiu a verdadeira natureza do poder no mundo hierarquizado e artificializado. Nele o predador se apresenta com toda a sua onipotência.

Spengler segue uma ordem organizacional que se estrutura historicamente, das tribos com seus chefes, à horda e, por fim, ao Estado organizado. Segundo o autor, “(...) do esmagamento dos vencidos emana a Lei que lhes é imposta. A lei humana é sempre a do mais forte, aquela perante a qual tem que se curvar o mais fraco; e essa lei reconhecida e instituída duradouramente entre os povos, constitui a paz" (SPENGLER, 1993, p. 87). Numa frase, Spengler resume o que entende por política: ela é a substituta temporária da guerra. Suas armas são a estratégia na forma da linguagem e das ações de cerco; armas intelectuais, que vão desde a propaganda, ideologias até aos meios menos letais como os controles de rotas, embargos econômicos, isolamentos estratégicos, etc.

O percurso, aparentemente, está feito. O predador está configurado: sua mão, sua linguagem e sua ação estão inexoravelmente vinculados. Ele criou um mundo - o da cultura,

(...) esse conjunto de processos artificiais, pessoais e autônomos de vida, transforma-se numa jaula de grades apertadas envolvendo essa alma rebelde a qualquer julgo. $\mathrm{O}$ animal predador, que transmutou os outros seres em animais domésticos, para deles se servir com proveito, tornou-se cativo de si próprio (SPENGLER, 1993, p. 89).

\begin{tabular}{|c|c|c|c|c|}
\hline Qevista Dialectus & Ano 9 & n. 17 & Maio - Agosto 2020 & p.244-257 \\
\hline
\end{tabular}


A humanidade se encontra aprisionada pela técnica - parte fundamental do ser predador. A técnica sofre no seu âmago de auto poiésis. Spengler afirma que ela não nos poupa trabalho,

(...) a própria essência da técnica humana, pessoal e evolutiva, contêm em si (...) a virtualidade de suas invenções despertarem a necessidade de novas descobertas, de qualquer desejo, ao ser satisfeito, suscitar milhares de outros, de cada triunfo sobre a natureza estimular ações para êxitos ainda maiores (SPENGLER, 1993, p. 89).

A alma do predador é insaciável, a maldição que pesa sobre os seus ombros é a mesma que permite a nobreza de se tornar quem se é. A última rebelião desse predador consiste em sua luta contra a própria cultura ou seu cativeiro ou ainda a massa. Segundo Spengler, a personalidade e o seu cultivo passam a ser um reduto da rebelião de alguns indivíduos, como é o caso dos boêmios e até dos criminosos, pois ou se assume a chefia das massas ou se empreende uma fuga dela ou ainda a despreza. Esse é o desenho que ele oferece, para visualizar e refletir.

Chega-se ao último ato: a ascensão e dissolução da cultura mecanicista. Lembremos que Spengler não presenciou a última revolução, a tecnológica. Ele ainda está inserido no seio da cultura mecanicista. Os efeitos das teorias de Einstein ainda não se fazem notar em seu momento histórico, mas ele percebe que se encontra no limiar de uma revolução profunda na humanidade. No início do capítulo ele faz uma revisão rápida de outras culturas ao longo da história.

Augusto Patrini Gomes, no seu artigo Decadência e história em $O$. Spengler, nos diz que o intelectual defende uma visão cíclica da história e da cultura. $\mathrm{Na}$ história universal ele identificou oito culturas (clássica ou antiga, egípcia, mexicana asteca e maia, chinesa, indiana, árabe ou mágica, babilônica e finalmente a ocidental). Todas passam por um período de nascimento, florescimento e morte; todas passam por evolução e decadência. Ele divide a história em épocas: espiritual, estética e política. Que, por sua vez, é dividida em fases: primavera caracterizada pela intuição, criação cultural e identitária poderosa, criatividade, unidade e abundância; o verão: caracterizado pelo amadurecimento, distinguido pela sociedade urbano-civil mais adiantada e pelo pensamento crítico; o outono, caracterizado pela ascensão urbana, e pelo ponto elevado de força organizacional disciplinada; o inverno, trata do enfraquecimento crescente da civilização cosmopolita e urbana, e exaustão da força

\begin{tabular}{|c|c|c|c|c|}
\hline Q Rovista Dialectus & Ano 9 & n. 17 & Maio - Agosto 2020 & p.244-257 \\
\hline
\end{tabular}


mental, além da ascensão da irreligiosidade, do ceticismo, do ecletismo e do vazio. Os dois primeiros foram associados à cultura e os dois últimos à civilização.

A cultura ocidental é denominada por Spengler de Fáustica, aquela que representa o triunfo do pensamento puramente técnico sobre os grandes problemas. Nela também se evidencia o combate entre homem e natureza, e este combate está sendo levado às últimas consequências; o resultado esperado é uma vitória, não do homem sobre a natureza, mas desta sobre o homem. Assim diz Spengler: “(...) é na cultura Fáustica, e só exclusivamente nela, que cada teoria é desde logo e também uma hipótese de trabalho" (SPENGLER, 1993, p. 100). Daí o desenvolvimento de toda ciência e toda técnica de Grosseteste a Roger Bacon, de Alberto Magno e Witelo a Francis Bacon: nelas se percebem as astúcias dos animais predadores intelectuais.

A cultura Fáustica representa o domínio do homem sobre a natureza. Os meios de domínio e, ao mesmo tempo, o afastamento de Deus e a criatura colocando-se como criador. De acordo com Spengler, aqueles que não sentiam em si a vontade de domínio sobre a natureza atribuíra a este projeto uma virtualidade diabólica.

São exemplos dessa época, por volta de 1500, a era dos povos vikings, Vasco da Gama, Cristóvão Colombo; a pólvora e a imprensa já criadas; Copérnico e Galileu e todas as descobertas que se sucedem a esse período. A cultura materialista impera e nos termos de Spengler resumindo a cultura materialista que imperará, indica: “(...) a técnica é imortal e eterna como Deus onipotente, traz a salvação a humanidade como o filho de Deus e ilumina como o Espírito Santo" (SPENGLER, 1993, 104), e é adorada pelo moderno filisteu do progresso.

Por fim, a técnica é também o maior dos luxos de nossa civilização. Esse luxo tem um preço alto que todos pagam. O mundo passa a ser controlado por poucos que o dirigem e decidem o destino da maioria. Os produtos gerados pela tecnologia sofrem cada vez mais desgastes, não necessariamente do material em si, mas da necessidade de inovação que é inerente ao próprio processo de produção e circulação da mercadoria produzida. A técnica controla, contemporaneamente, e carregará o selo da ideologia, como mostraram tanto Marx, no capítulo de $O$ Capital, sobre Maquinaria e grande indústria, Marcuse em Unidimensionales Mensch e Habermas em Técnica e ciência como ideologia.

\section{Considerações Finais}

\begin{tabular}{|c|c|c|c|c|}
\hline Q Rovista Dialectus & Ano 9 & n. 17 & Maio - Agosto 2020 & p.244-257 \\
\hline
\end{tabular}


Spengler, em $O$ homem e a técnica, nos alerta para a tragédia que é viver sob o signo da técnica. Nos seus termos, “(...) qualquer cultura superior é uma tragédia” (SPENGLER, 1993, p. 107). A história da humanidade é trágica. Os polos opostos estão permanentemente ativos. Conforme Spengler: “(...) o microcosmo-homem se revoltou contra a natureza, agora o microcosmo-máquina se subleva contra o homem nórdico" (SPENGLER, 1993, 107).

Apesar de todo o seu pessimismo, Spengler nos alerta para situações que são reais e efetivas hoje, como, por exemplo, o domínio político que se efetiva de forma tecnocrática. Basta que acompanhemos as decisões políticas (especialmente em períodos de pandemia) e a ingerência da técnica nas decisões ou nos projetos políticos para nações inteiras, a valoração dos saberes que produzem algo técnico, a pressão pela inovação nas pesquisas e para resultados impliquem produtos reais, palpáveis ou estratégicos. Nenhuma outra forma de saber é legítima se ela não apresenta resultados palpáveis.

Spengler (1993, p. 108) lembra que é

(...) posta em relevo a conexão estreita e profunda, a quase total identidade entre a política, a guerra e a economia. (...) os povos industrialmente pobres passam privações em todos os aspectos; não têm meios para a manutenção de um exército nem para fazer guerra, pelo que são politicamente impotentes.

A técnica está presente em todos os níveis da política, da economia e, obviamente, das formas de guerrear.

Spengler é considerado por muitos como um pensador pessimista. Se ele de fato o é, se deve muito mais ao que ele foi capaz de presenciar no seu tempo, marcado pela desesperança e pela morte da cultura e pela ampliação da civilização tecnológica, do que pelo que ele foi capaz de apontar como projeção de uma visão de mundo. Se hoje ele se encontra no ostracismo, deve-se a muitos aspectos de seu pensamento que foram deslegitimados por pesquisas em áreas específicas das ciências naturais e por um apego a um modelo centralizador de política. Como estudiosos, podemos ainda perceber que ele contribuiu para que pudéssemos estudar esse tema da técnica.

A contribuição de Spengler se fez notar, principalmente, na Alemanha atribulada dos anos vinte. Se sua obra não é um retrato fiel da época, pelo menos se destaca como uma crença na capacidade humana, mediada pela técnica, e pela

\begin{tabular}{|c|c|c|c|c|}
\hline Qovista Dialectus & Ano 9 & n. 17 & Maio - Agosto 2020 & p.244-257 \\
\hline
\end{tabular}


compreensão do homem como predador e, como tal, não se deixará abater pelos desafios que são postos durante a primeira grande guerra e pela derrota que adveio dela. A esperança do homem predador consistirá em desenvolver um conjunto de técnicas adequadas para lidar com o novo momento. Certamente o progresso técnico se fez notar, principalmente no fim da segunda guerra, com as bombas de Hiroshima e Nagasaki. A superioridade bélica indica superioridade técnica e, consequentemente, política. Desse modo, a visão de Spengler nos permitiu fazer essa passagem da condição humana para o domínio político mediado agora pelo desenvolvimento da ciência e da técnica.

\section{Referências}

BRÜSEKE, Franz. A modernidade técnica. Revista brasileira de ciências sociais, São Paulo, vol. 17 n. 49. 135-144, 2002.

Ética e Técnica? Dialogando com Marx, Spengler, Jünger, Heidegger e Jonas. In: Ambiente \& Sociedade, Vol. VIII, nº. 2, jul./dez. 2005.

CHOMSKY, Noam.Estruturas Sintáticas. Petrópolis: Vozes, 2015.

Linguagem e mente. 3. Ed. São Paulo: Unesp, 2009.

Reflexões sobre a linguagem.São Paulo: Cultrix, 1980.

GOMES, Augusto Patrini Menna Barreto. Decadência e História em Oswald Spengler. In: Anais do XXVI Simpósio Nacional de História - ANPUH - São Paulo, julho 2011.

O conceito de história em Oswald Spengler. 2013 (Dissertação) - Mestrado em História Social, Universidade de São Paulo (USP), São Paulo.

HABERMAS, Jürgen. Técnica e Ciência como ideologia. Lisboa: Edições 70, 1968.

NITSCHAK, H. Antropofagia cultural y tecnologia. Universum, Talca, v. 31, n. 02, p. 157-171, 2016.

HEIDEGGER, Martin. A questão da técnica. In: Ensaios e conferências. 2. Ed. São Paulo:2002. pp. 11-38.

Nietzsche: metafísica e Niilismo. Rio de Janeiro: ReluméDumará, 2000.

MARCUSE, Herbert. A Ideologia da Sociedade Industrial. Rio de Janeiro: Zahar, 1964.

\begin{tabular}{|c|c|c|c|c|}
\hline Qovista Dialoctus & Ano 9 & n. 17 & Maio - Agosto 2020 & p.244-257 \\
\hline
\end{tabular}


SPENGLER, Oswald. O homem e a técnica. 2. Ed. Trad. Portuguesa de João Botelho, Lisboa: Guimarães Editores, 1993.

A decadência do ocidente. Rio de Janeiro: Zahar, 1964.

SWER, G. M. Technology and the End of Western Civilisation: Spengler's and Heidegger's Histories of Life/Being. Indo-Pacific Journal of Phenomenology, Bunbury - Australia, v. 19, n. 01, p. 01-10, Agosto 2019. ISSN 20797222. 